Review

\title{
Natural phytochemicals and probiotics as bioactive ingredients for functional foods: Extraction, biochemistry and protected-delivery technologies
}

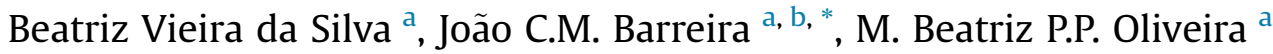 \\ ${ }^{a}$ REQUIMTE, Departamento de Ciências Químicas, Faculdade de Farmácia, Universidade do Porto, Rua Jorge Viterbo Ferreira, $n^{\circ} 228,4050-313$ Porto, \\ Portugal \\ b CIMO-ESA, Instituto Politécnico de Bragança, Campus de Santa Apolónia, Apartado 1172, 5301-855 Bragança, Portugal
}

\section{A R T I C L E I N F O}

\section{Article history:}

Received 20 October 2015

Received in revised form

15 December 2015

Accepted 15 December 2015

Available online 2 February 2016

\section{Keywords:}

Functional foods

Bioactive compounds

Extraction techniques

Encapsulation methodologies

\begin{abstract}
A B S T R A C T
Background: The well-known correlation between diet and physiology demonstrates the great possibilities of food to maintain or improve our health, increasing the interest in finding new products with positive physiological effects. Nowadays, one of the top research areas in Food Science and Technology is the extraction and characterization of new natural ingredients with biological activity that can be further incorporated into a functional food, contributing to consumer's well-being. Furthermore, there is a high demand for effective encapsulation methodologies to preserve all the characteristics of bioactive compounds until the physiological action site is reached.

Scope and approach: In this review, the relevance of developing standard approaches for the extraction of the highly diverse bioactive compounds was described, as it defines the suitability of the following steps of separation, identification and characterization. Special attention was also dedicated to the encapsulation techniques used on hydrophilic and/or lipophilic compounds (e.g., emulsification, coacervation, supercritical fluid, inclusion complexation, emulsification-solvent evaporation and nanoprecipitation). Key findings and conclusions: Some useful conclusions regarding the selection of the best extraction methodology (Soxhlet extraction, ultrasound-assisted extraction, supercritical fluid extraction, accelerated solvent extraction, or shake extraction) were achieved, considering important aspects such as cost, required technical skills, extract integrity, green chemistry principles, solvent type, sample size, $\mathrm{pH}$, temperature and pressure. In addition, this comprehensive review allowed defining the best protective approach to solve the limitations related to the extremely low absorption and bioavailability of bioactive phytochemicals, overcoming problems related to their low solubility, poor stability, low permeability and metabolic processes in the GI tract.
\end{abstract}

(C) 2016 Elsevier Ltd. All rights reserved.

\footnotetext{
Abbreviations: ADA, American Dietetic Association; AP1, activator protein 1; APC, antigen presenting cell; ARE, antioxidant response elements; ASE, accelerated solvent

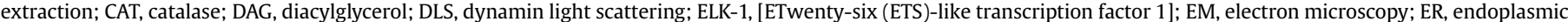

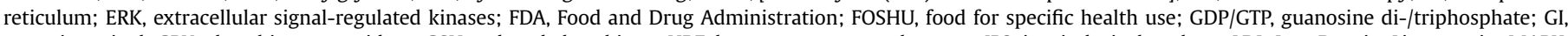

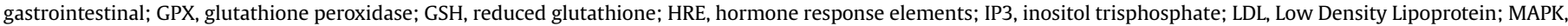

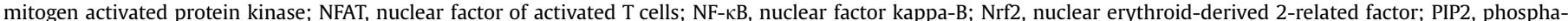

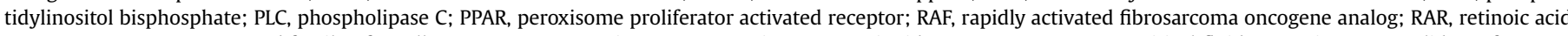

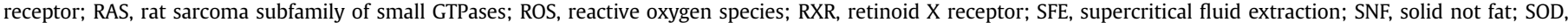
superoxide dismutase; Th, T-helper cells; UAE, ultrasound assisted extraction; WHO, World Health Organization.

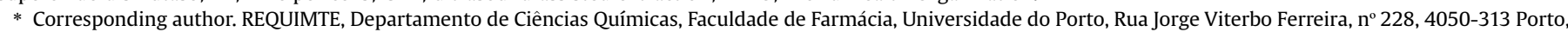
Portugal.
}

E-mail address: jbarreira@ipb.pt (J.C.M. Barreira). 


\section{Introduction}

Plants and their constituents have a key position in the progression of modern studies and knowledge on biological activity or active substances. Plant species are important sources of food, medicinal and supplementary health products, and their bioactive compounds are themselves products of metabolism, acting in similar ways to those operating in humans and animals (GuribFakim, 2006).

The emergency of dietary compounds with health benefits offers an excellent opportunity to improve public health (Chen, Remondetto, \& Subirade, 2006). Despite the dynamics of nutraceutical substances in physiological functions is not yet fully understood, their addition in food matrices is acknowledged as holding high potential to decrease disease risk. Accordingly, the scientific community should provide the necessary bases to develop innovative functional foods with the potential to produce physiological benefits or reduce the long-term risk of diseases onset (Elliott \& Ong, 2002).

The effectiveness of nutraceutical products in preventing diseases depends on preserving the stability, bioactivity and bioavailability of the active ingredients (Fang \& Bhandari, 2010). This represents a formidable challenge because only a small proportion of molecules remains available after oral administration, usually due to insufficient gastric residence time, low permeability and/or solubility in the gut, as well as instability under conditions encountered in food processing or in the gastrointestinal (GI) tract (Leonard, 2000).

Besides phytochemicals, probiotic delivery systems have also been widely used with the main target of reinforcing the natural intestinal flora. These systems are usually categorized in conventional (pharmaceutical formulations) and non-conventional (mainly food-based) products. Their effectiveness in improving the health status depends mainly on their ability to deliver viable functional bacteria, overcoming the harsh effects of GI. Probiotics have been increasingly used, but they present two sets of problems: i) their size, and ii) the need to be kept alive (Champagne \& Fustier, 2007). The delivery of these agents will therefore require food formulations and production techniques to provide protective mechanisms that maintain the active molecular form until the time of consumption and its release in the physiological target within the organism (Chen et al., 2006; Leonard, 2000). Once encapsulated in a biodegradable polymer, cells are easier to handle than in a suspension and their presence in microparticles can be quantified, allowing the control of their dosage. In addition, their incorporation enhances the survival of cells during processing and storage (Anal \& Singh, 2007).

Besides the benefits of encapsulating living cells, incorporation of bioactive compounds such as vitamins, prebiotics, bioactive peptides, non-nutrient carotenoids, phenolic compounds, phytoestrogens, glucosinolates, phytosterols, fatty acids or structured lipids into food systems, provides a way to develop novel functional foods that may have physiological benefits or reduce the disease' risk (Chen et al., 2006).

\subsection{Bioactive compounds isolated from plants}

Since the beginning of mankind, people use plants for their nutritional purposes. However, after discovering their medicinal properties, flora became a useful source of compounds with important roles in preventing/treating diseases and health improvement in several geographical locations. Actually, the ancestral use of herbal plants might be considered as the basis for using naturally bioactive molecules. In addition, the World Health Organization (WHO) predicts that $80 \%$ of the world population depends on traditional medicine as primary healthcare, mainly through the use of plant extracts and their bioactive compounds (Azmir et al., 2013).

All living things, from the bacterial cell to the millions of cells in plants, produce chemicals for their survival and livelihood. The compounds produced by biological systems are usually divided in two distinct groups: i) primary metabolites - chemical substances (e.g., carbohydrates, amino acids, proteins and lipids) essential for cell maintenance, growth and development; ii) secondary metabolites - substances with low-molecular-weight (e.g., phenolic acids, alkaloids or terpenes) relevant to increase the overall surviving and protection ability, by interacting with their surroundings (Azmir et al., 2013; Scalbert \& Williamson, 2000). The production of secondary metabolites in different species depends on their growth process and the particular requirements of the species. Several studies have shown that the production of secondary metabolites depends also on the climate, soil and crop conditions (for instance, plants growing in harsh environments produce a greater number of antioxidants) (Azmir et al., 2013). Furthermore, and independently of the raw material, the qualitative and quantitative studies of bioactive compounds from plant materials depend mostly on the selection of proper extraction methods. These methods are usually affected by common factors, such as the matrix properties of the botanical source, solvent, temperature, pressure and time (Hernández, Lobo, \& González, 2009). The extraction conditions are so determinant, that the bioactive plant compounds might be classified according to the type of extraction: i) hydrophilic or polar compounds (e.g., phenolic acids, flavonoids, organic acids, sugars); ii) lipophilic or nonpolar compounds (e.g., carotenoids, alkaloids, terpenoids, fatty acids, tocopherols, steroids). Another common classification criterion is categorizing the bioactive plant compounds according to their distribution in nature: i) shortly distributed (simple phenols, pyrocatechol, aldehydes); ii) widely distributed (flavonoids, phenolic acids); and iii) the least abundant polymers (tannin and lignin) (Bravo, 1998; Sánchez-Moreno, 2002).

In general, bioactive compounds of plants might be defined as secondary metabolites that cause pharmacological or toxicological effects in human and animals, which can be identified and characterized from extracts of roots, stem, bark, leaves, flowers, fruits and seeds (Bernhoft, 2010).

In the next section, special attention will be given to the particular cases of phenolic compounds and sterols, which represent two of the main classes of phytochemicals with a proven track of success as ingredients in functional foods formulations.

\subsubsection{Phenolic compounds}

Phenolic compounds are plant secondary metabolites commonly found in plants and derived products such as berries, apples, citrus fruit, cocoa, grapes, onions, olives, tomatoes, broccoli, lettuce, soybeans, grains and cereals, green and black teas, coffee beans and red and white wines (Birt, Hendrich, \& Wang, 2001). It has been estimated that about 8000 compounds naturally occurring in plants are phenols (Arceusz, Wesolowski, \& Konieczynski, 2013). Their characteristic structural feature is an aromatic ring with varying hydroxyl-substitutions. Despite occurring in free form, these compounds appear mainly in their bound forms, for example as glycosides or esters (Morton, Caccetta, Puddey, \& Croft, 2000). Phenolic compounds might be produced from two distinct pathways: i) shikimic acid (phenylpropanoids); ii) acetic acid (phenols) (Sánchez-Moreno, 2002). According to their carbon chain, phenolic compounds can be divided in 16 major classes (Table 1). These compounds have diverse biological activity, being mainly acknowledged for their preventing action against the damage caused by oxidative stress. Other relevant functions in 
plants include acting on the sensory properties, defining the attractive colour of leaves, fruits and flowers, providing resistance against pesticides and predators, controlling germination, growth and reproduction processes. Due do their several physiological roles, phenolic compounds are essential for the major cellular metabolism processes (Dicko, Gruppen, Traoré, Voragen, \& van Berkel, 2006).

Phenolic acids have a benzene ring, a carboxylic group and one or more hydroxyl and/or methoxyl groups, being usually divided in two groups: i) benzoic acids; ii) hydroxycinnamic acids. The benzoic acids have seven carbon atoms $\left(C_{6}-C_{1}\right)$, while hydroxycinnamic acids have nine carbon atoms $\left(\mathrm{C}_{6}-\mathrm{C}_{3}\right)$, but the most commonly found in vegetables present seven carbon units (Yang, Landau, Huang, \& Newmark, 2001), where they are rarely found in the free form (commonly present as esterified compounds). Phenolic acids may be about one-third of the phenolic compounds in the human diet, where these substances have a high antioxidant activity (Bravo, 1998; Giada, 2013).

Flavonoids are the most common and widely distributed group of plant phenolic compounds. Their general structure, as phenylpropanoid derivatives, consists of a fifteen-carbon skeleton with two benzene rings linked via a heterocyclic pyran ring (Fig. 1). They comprise a large class of plant secondary metabolites with relevant action on the plant defence system, having been reported as important constituents of the human diet (Giada, 2013).

The chemical nature of flavonoids depends on their structural class, according to the degree of methylation, hydrogenation and hydroxylation and other substitutions and conjugations. Flavonoids can be divided into a variety of classes such as: flavones, flavanols, flavonols, flavanonols, flavanones, isoflavones or anthocyanins (Table 2) (Kumar \& Pandey, 2013; Scalbert \& Williamson, 2000) with different antioxidant, antibacterial, antiviral and anticancer activities (Giada, 2013; Kumar \& Pandey, 2013). Flavonoids occur mainly as aglycones, but they exist also as glycosides and methylated derivatives (Kumar \& Pandey, 2013; Scalbert \& Williamson, 2000). These compounds have attracted interest due to the discovery of their pharmacological activities and health regulation function. Regarding their biological activity, they were previously reported as having antioxidant, hepatoprotective, antibacterial, anti-inflammatory, anticancer and antiviral effects, besides inhibiting lipid peroxidation (Gurib-Fakim, 2006). Furthermore, flavonoids can act as growth regulators in plants (Kumar \& Pandey, 2013). When added to food products, flavonoids are responsible for preventing fat oxidation and protecting vitamins and enzymes, while also contributing for food colour and taste. The absorption of dietary flavonoids, which occurs mainly in the small intestine, depends on their physiochemical properties. The aglycone form is easily absorbed, while the glycosylated molecules need to suffer a previous deglycosylation step. After absorption, flavonoids are conjugated in the liver or metabolized to smaller compounds (Kumar \& Pandey, 2013).

Tannins are another well-known example of phenolic compounds with intermediate to high molecular weight. These compounds are usually classified in two major groups: i) hydrolysable tannins; ii) non-hydrolysable tannins or condensed tannins (Chung, Wong, Wei, Huang, \& Lin, 1998). Hydrolysable tannins have a centre of glucose or a polyhydric alcohol partially or completely esterified with gallic acid or hexahydroxydiphenic acid, forming gallotannin and ellagitannins (Table 1) (Okuda, Yoshida, \& Hatano, 1995). Condensed tannins are polymers of catechin and/or leucoanthocyanidin that constitute the main phenolic fraction responsible for the characteristic astringency of the vegetables. These substances are polymeric flavonoids that form the anthocyanidins pigments (Stafford, 1983). Although the antioxidant activity of tannins has been less reported than the activity of flavonoids, recent research studies have shown that the degree of polymerization is related with the antioxidant activity - in condensed and hydrolysed tannins of high molecular weight, this activity can be up to 15-30 times superior to that attributed to simple phenols (SánchezMoreno, 2002).

As it would be easily anticipated, considering the diverse biological activity of phenolic compounds, their incorporation into food products is largely studied. Some of the most relevant examples include meat and fish products, pasta (Day, Seymour, Pitts, Konczak, \& Lundin, 2009), ice cream, cheese, yogurt and other dairy products (Çam, Içyer, \& Erdoğan, 2014; Caleja et al., 2015; Karaaslan, Ozden, Vardin, \& Turkoglu, 2011).

\subsubsection{Sterols}

Phytosterols, which include plant sterols and stanols (Jones \& AbuMweis, 2009), are currently among the most successful phytochemicals for the development of functional foods with unique health claims (Gurib-Fakim, 2006). They are a member of the triterpene family of natural products and are important structural components of plant membranes to stabilize phospholipid bilayers in plant cell membranes, just as cholesterol does in animal cells. These components occur naturally in plants, mainly in free and esterified forms (de Smet, Mensink, \& Plat, 2012), being included in the nonsaponifiable fraction of plant oil (Jones \& AbuMweis, 2009). This family includes more than 200 different phytosterols and more than 4000 other types of triterpenes (Moreau, Whitaker, \& Hicks, 2002).

Structurally, phytoesterols are similar to cholesterol and contain 28 or 29 carbons and one or two $\mathrm{C}-\mathrm{C}$ double bonds, typically one in the sterol nucleus and sometimes a second in the alkyl side chain (Barreira \& Ferreira, 2015). They are not synthetized in humans, being also poorly absorbed and excreted faster from the liver than cholesterol. When incorporated as a functional food ingredient, plant sterols and stanols are frequently esterified with a fatty acid ester to increase the solubility in the food matrix (Jones \& AbuMweis, 2009; de Smet et al., 2012). Furthermore, dietary phytosterols were reported as inhibiting the uptake of both dietary and endogenously produced cholesterol on the intestinal cells and several studies suggest a protective role of phytosterols against colon, prostate and breast cancer (Jones \& AbulMweis, 2009).

Phytosterols have been included in several food matrices with different degrees of effectiveness. While their incorporation in chocolate, orange juice, cheese, non-fat beverages, meats, croissants and muffins, oil in bread and cereal bars did not allow great results (considered as cholesterol lowering), when added to fat spreads, mayonnaise, salad dressings, milk and yoghurt, the obtained results were more satisfactory (Jones \& AbuMweis, 2009).

\subsection{Probiotics, prebiotics and lactic products}

Due to their availability in different formulations, lactic products are one of the top examples of functional foods. Based on their mechanism of action, lactic fermentation products are usually classified in three groups (Mitsuoka, 2014): i) probiotics: viable microorganisms such as lactobacilli and bifidobacteria that benefit the host by improving the intestinal bacterial balance; these live microbial feed supplements associate naturally with the intestinal mucosa, improving the intestinal microbial balance. Because of their perceived health benefits, probiotic bacteria have been increasingly incorporated into a range of products including yogurts, cheeses, ice cream, milk powders and frozen dairy desserts (Brannon-Peppas, 1995; Desmond et al., 2005); ii) prebiotics: nondigestible food ingredients, such as oligosaccharides and dietary fibre, that selectively stimulate the growth or activities of useful 
Table 1

Basic structures of some common phenolic compounds.

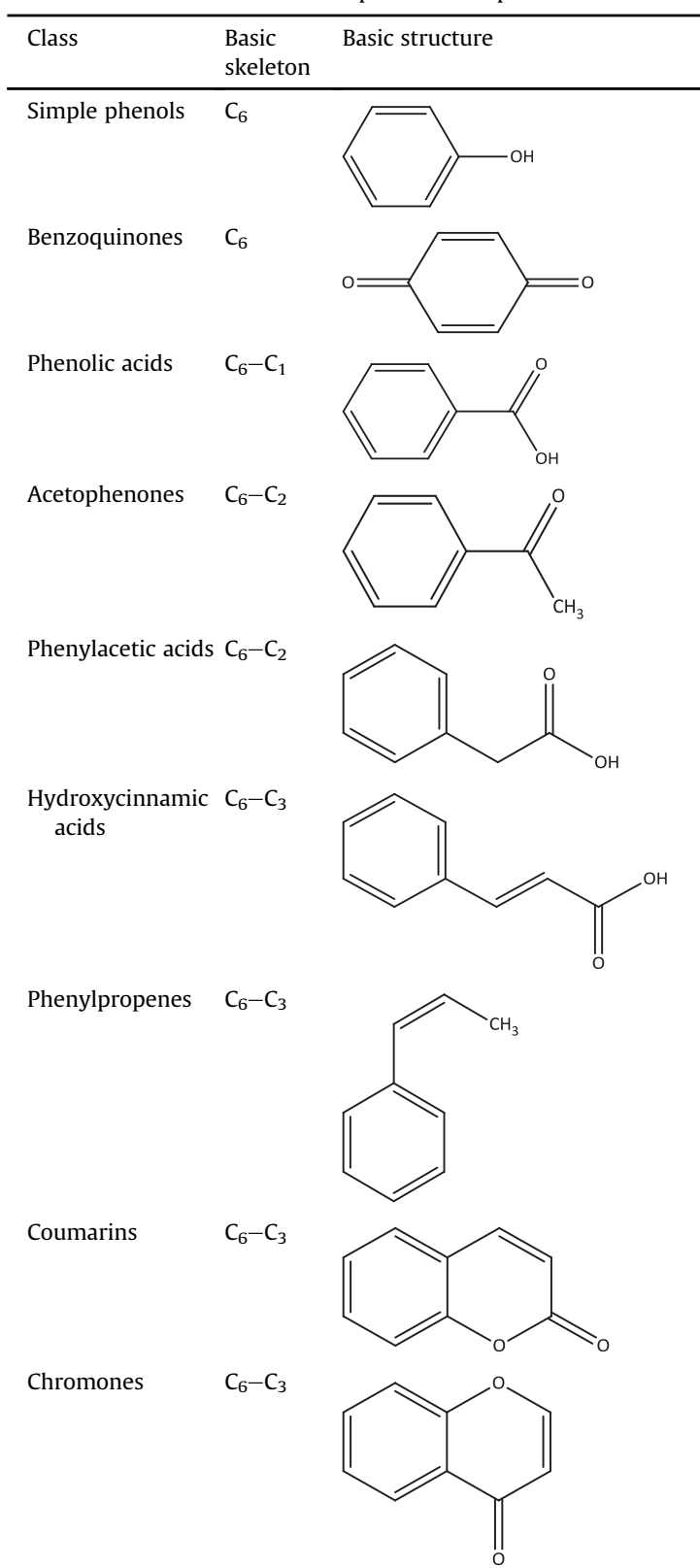

Naphthoquinones $\mathrm{C}_{6}-\mathrm{C}_{4}$<smiles>O=C1C=CC(=O)c2ccccc21</smiles>

Xanthones<smiles>O=c1c2ccccc2oc2ccccc12</smiles> 
Table 1 (continued)

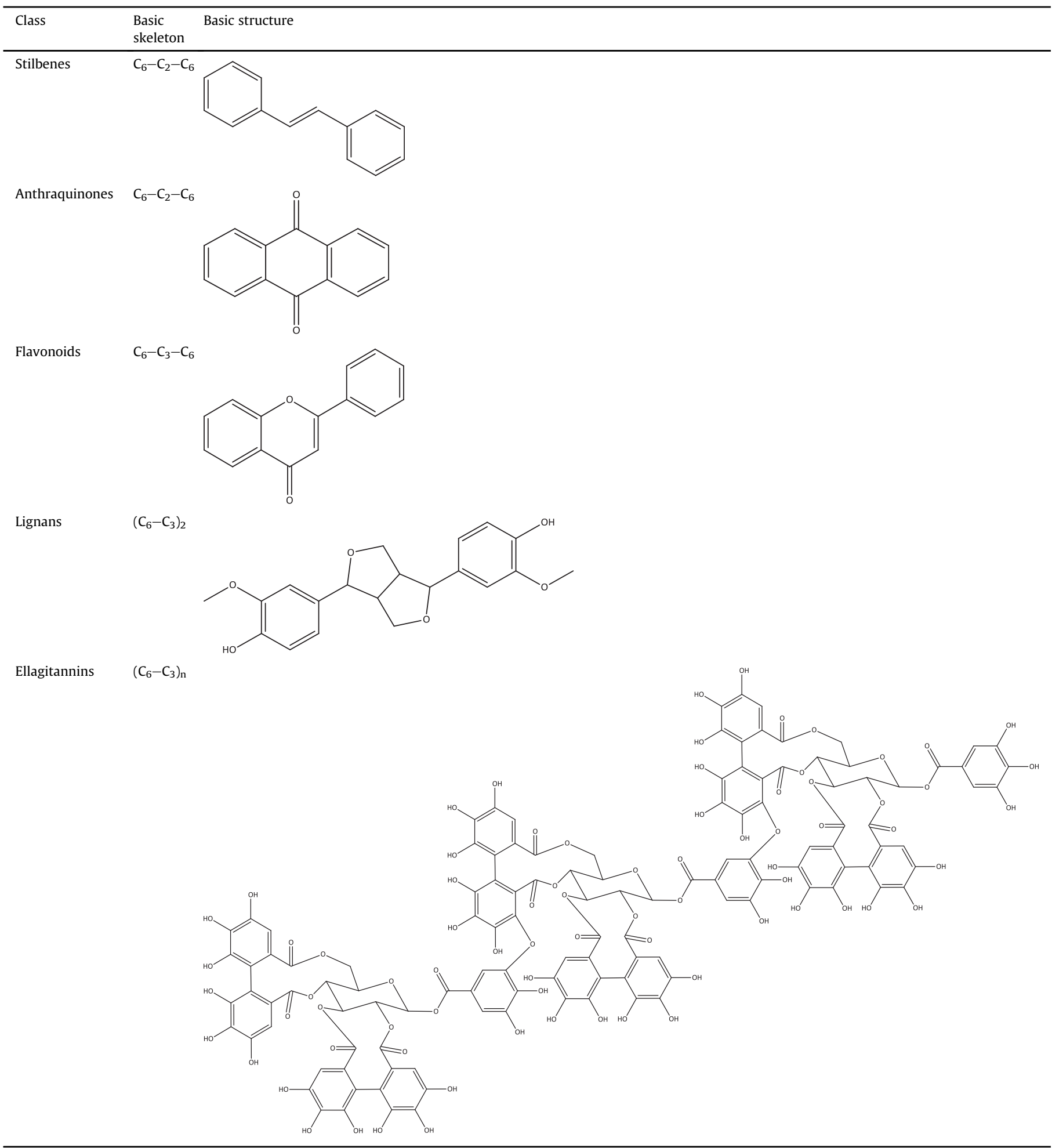

intestinal bacteria in the colon, by providing growth enhancers and nutrients to probiotic bacteria. Basically, prebiotic are nondigestible carbohydrates, mainly obtained by extraction from plants, followed by enzymatic hydrolysis (Gurib-Fakim, 2006); iii) biogenics: biologically active molecules such as peptides, flavonoids and carotenoids, that favour the host by direct immunostimulation, suppression of mutagenesis, tumorigenesis, peroxidation or intestinal putrefaction.

Probiotics and prebiotics improve the balance of the intestinal microbiota by enhancing the growth of beneficial bacteria and inhibiting the development of harmful bacteria (immunostimulation), besides inducing the production of biogenics such as antibacterial substances and immunopotentiators (Mitsuoka, 2014). While the positive effects of the oral ingestion of bacteria have been 
<smiles>O=c1cc(-c2ccccc2)oc2ccccc12</smiles><smiles>O=c1c(O)c(-c2ccccc2)oc2ccccc12</smiles><smiles>O=C1c2ccccc2OC(c2ccccc2)C1O</smiles><smiles>O=c1c(-c2ccccc2)coc2ccccc12</smiles>

Fig. 1. General structure of flavonoids and basic structures of some of the most common subgroups.

widely debated, more health benefits have been shown to exist above gut-specific functions and immunological functions leading to the belief that probiotics have functional benefits at both cellular and molecular levels (Panigrahi et al., 2007). In fact, the use of probiotics may cause cell-mediated immune responses and treatments for several human intestinal dysfunctions (Kalliomäki, Salminen, Poussa, Arvilommi, \& Isolauri, 2003). Furthermore, these agents have the potential to act as delivery systems for vaccines and prevent the conditions caused by pathogenic organisms in the intestine. The ability of probiotic microorganisms to survive and multiply in the host strongly influences their benefits. Probiotic bacteria, besides the immunological effects and the prevention, protection and eradication of pathogenic bacteria, have been linked to cancer therapy, besides having been found to be therapeutic in patients with high cholesterol levels (Govender et al., 2014).

The bacteria associated to these functions, which mainly belong to Lactobacillus and Bifidobacterium genera (Table 3), have several typical characteristics: metabolic stability, adherence to the intestinal cell walls, not promoting antibiotic resistance, nonpathogenic, being safe for consumption and effective in providing health benefits. In addition, these bacteria should be active in the product, survive along the upper digestive tract, resist to the gastric acid bile, oxygen and enzymes, being able to co-aggregate as part of the natural gut flora and have beneficial effects after adhering to the intestine of the host (Govender et al., 2014; Mitsuoka, 2014). However, there are still several problems regarding the low viability of probiotic bacteria in dairy foods, which might be severely affected by different factors, including $\mathrm{pH}$, dissolved oxygen concentration, storage temperature, species and strains of associative fermented dairy product organisms. Therefore, several approaches designed to increase the resistance of these probiotics have been proposed, including an appropriate selection of acid and bile resistant strains, stress adaptation, incorporation of micronutrients and microencapsulation (Gismondo, Drago, \& Lombardi, 1999).

In fact, there are many systems for the delivery of probiotics to the GI system, which are categorized in two groups: i) nonconventional commercial formulations, consisting mainly of foodbased-products (cheeses, yogurts, creams, chocolates, milk and meat, among others), many of which produced using probiotic bacteria; ii) conventional pharmaceutical systems (e.g., beads, capsules and tablets), usually more effective in this regard and more well-characterized, comparing to commercial food-basedcarrier systems. Each type of formulation has been found to possess advantages in the delivery of probiotics, with each one showing differences in their effectiveness to deliver the correct amount of bacteria to the human intestinal system as well as in providing protection to the dosed probiotic bacteria (Govender et al., 2014).

\section{Extraction of bioactive compounds}

The high variability of bioactive compounds demands developing suitable standard approaches for their extraction. In fact, the quality of the further steps of separation, identification and characterization of bioactive compounds is highly dependent on the suitability of the extraction process. All available techniques are aimed at common objectives such as extracting target compounds, increasing the selectivity of analytical methods and the sensitivity of the forwardly performed bioassay, converting the bioactive compounds into more suitable forms for detection and separation and providing a strong and reproducible method (Chester, Pinkston, \& Raynie, 1996).

Some of the most applied methods include:

i) Soxhlet extraction, usually with hexane, petroleum ether, ethyl acetate, or methanol; this methodology allows performing several extractions cycles with "renewed" solvent, but the process is too long and the solvents are costly. This methodology is usually employed to extract the lipophilic components, using hexane or petroleum ether as solvents. However, it might also be used for polar compounds, as in the case of specific phenolic compounds which proved to be effectively extracted with methanol (Arceusz et al., 2013). Recently, it was also applied to extract volatile compounds (Wu, Wang, Liu, Zou, \& Chen, 2015).

ii) Ultrasound-assisted extraction (UAE), based in using ultrasonic vibrations toward an extracted sample. Despite being highly dependent on the type of solvent, sample size, $\mathrm{pH}$ of extract, temperature and pressure, it is fast, simple and allows extracting several samples simultaneously; it is often performed with methanol, acetone, water and ethyl acetate. 
Table 2

Main classes of flavonoids.

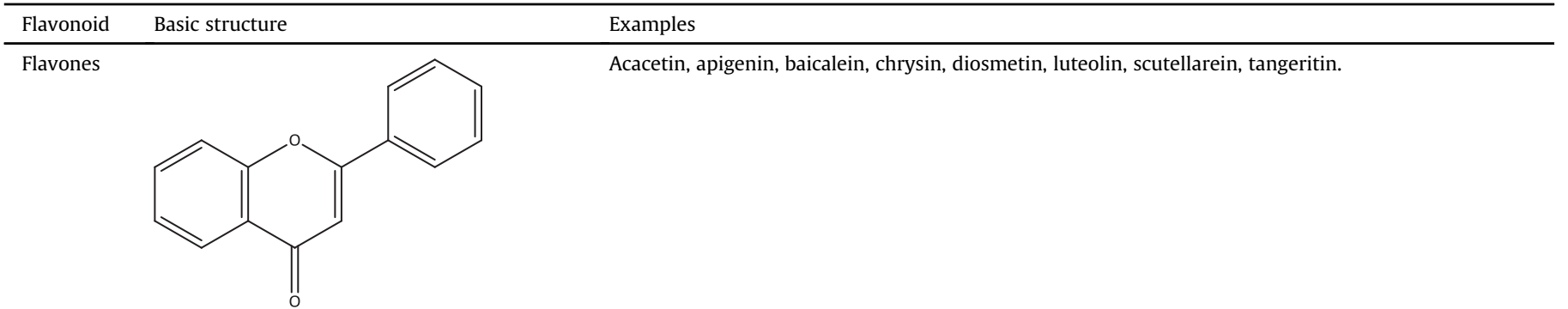

Flavonols<smiles>O=c1c(O)c(-c2ccccc2)oc2ccccc12</smiles>

Flavanols<smiles>OC1Cc2ccccc2OC1c1ccccc1</smiles>

Flavanones<smiles>O=C1C[C@H](c2ccccc2)Oc2ccccc21</smiles>

Flavanonols<smiles>O=C1c2ccccc2O[C@H](c2ccccc2)[C@@H]1O</smiles>

Isoflavones<smiles>O=c1c(-c2ccccc2)coc2ccccc12</smiles>

Azaleatin, fisetin, galangin, kaempferol, morin, myricetin, quercetin, rhamnetin.

Catechin, epichatechin, epigallocatechin, proanthocyanidins, theaflavins, thearubigins.

Butin, eriodictyol, hesperetin, homoeriodictyol, isosakuranetin, naringenin, pinocembrin, sakuranetin, sterubin.

Astilbin, taxifolin.

Biochanin A, daidzein, genistein, glycitein, prunetin, puerarin, formononetin.

Cyanidin, delphinidin, malvidin, pelargonidin, peonidin, petunidin

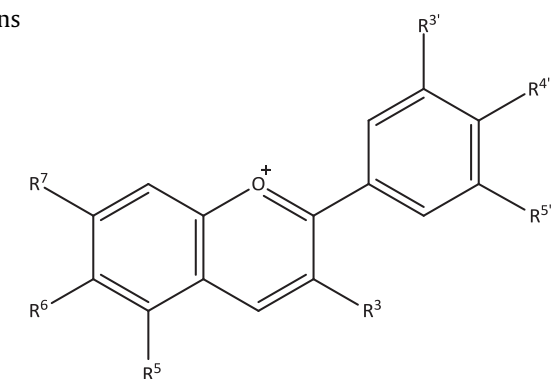


Table 3

Microorganisms applied in fermented milks, lactic milk drinks, pasteurized sour milk and lactic fermentations products.

\begin{tabular}{lll}
\hline Lactobacillus & Bifidobacterium & Other species \\
\hline L. acidophilus & B. adolescentis & Enterococcus faecalis \\
L. amylovarus & B. animalis & Enterococcus faecium \\
L. casei & B. bifidum & Lactococcus lactis \\
L. crispatus & B. breve & Leuconostoc mesenteroides \\
L. delbrueckii ss. bulgaricus & B. infantis & Sporolactobacillus inulinus \\
L. gallinarum & B. lactis (animalis) & Streptococcus thermophilus \\
L. gasseri & B. longum & Clostridium butyricum \\
L. johsonii & B. thermophilum & Bacillus cereus var. toyoi \\
L. paracasei & B. pseudolongum & Escherichia coli Nissle \\
L. plantarum & & Saccharomyces cerevisiae \\
L. reuteri & & Saccharomyces boulardii \\
L. rhamnosus & & \\
\hline
\end{tabular}

This technology has been successfully applied to extract different bioactive compounds such as carotenoids, polysaccharides, proteins, phenolic compounds, aromatic compounds or sterols (Vilkhu, Mawson, Simons, \& Bates, 2008; Villares, García-Lafuente, Guillamón, \& Ramos, 2012; Wu et al., 2015).

iii) Supercritical fluid extraction (SFE), usually performed with carbon dioxide under high pressure, allows working with low temperatures, high selectivity, low solvent volume, small samples, short extraction times and automation; nevertheless, its effectiveness is affected by several parameters such as pressure, temperature, time and solubility (Arceusz et al., 2013). The first application of SFE to foodstuff dates back from the early 1970s, when this technique was used in the decaffeination of coffee beans. Afterwards, when SFE was recognized as a "green" procedure, its application was boosted and several nutraceutical ingredients, e.g., carotenoid pigments, sterols, tocopherols, or polyphenolic compounds were extracted using this methodology (Srinivas \& King, 2010).

iv) Accelerated solvent extraction (ASE), is made with the same solvents, but using higher pressure and elevated temperatures, presenting the additional advantages of enabling the extraction of fresh samples, shorter extraction times, higher automation and good extraction kinetics. Several types of compounds have been extracted with this technique, but some of the most commonly reported include vitamins (Jäpelt \& Jakobsen, 2016), phenolic compounds (Arceusz et al., 2013; Nayak et al., 2015) and carotenoids (Saha, Walia, Kundu, Sharma, \& Paul, 2015).

v) Shake extraction, in this type of extraction, a shaking device is used, allowing more effective extractions and shortening the required time. The main advantage of this technique is the increase in the surface are where the solvent interacts with the plant material. The high variety of shaking devices or available solvents make it suitable for a high diversity of components. However, there is a relevantly higher number of reports describing its application to extract phenolic compounds (Arceusz et al., 2013).

\section{Development of functional foods from plant bioactive compounds}

\subsection{Functional foods}

Despite the lack of an exact definition for functional foods (except in Japan, where the concept Food for Specific Health Use,
FOSHU, is well established), the following working definition: "A functional food is, or appears similar to, a conventional food. It is part of a standard diet and is consumed on a regular basis, in normal quantities. It has proven health benefits that reduce the risk of specific chronic diseases or beneficially affect target functions beyond its basic nutritional functions." stands as the most generally accepted (Doyon \& Labrecque, 2008). Accordingly, it is possible to say that a given food might be considered as functional when, besides its nutritional effects, it exerts one or more target functions in the body, thereby improving health status or minimizing disease risk. The American Dietetic Association (ADA), in 2004, suggests that the "term functional food should not be used to imply that there are good and bad foods ( ... ) all food can be incorporated into a healthful eating plan, the key being moderation and variety". Several organisations accept that functional foods are "foods or ingredients of foods that provide an additional physiological benefit beyond their basic nutrition" (ILSI, 1999).

It is important to distinguish functional food from nutraceutical. In practical terms, functional foods are foods or beverages with a specific effect (scientifically verified), whereas nutraceuticals may be produced from foods, being characterized as bioactive components obtained from a functional food with a well-defined activity and marketed in concentrated form as pills, capsules, powders, tinctures etc. either as single or mixed preparations (Gurib-Fakim, 2006). Nutraceuticals were also defined as dietary substances that deliver a concentrated form of a bioactive substance in quantities that exceed those obtained from food (Govender et al., 2014).

The market for functional ingredients and foods has experienced an amazing growth in recent years due to the increased consumers' awareness and the interest in promoting healthy diets and lifestyle. The development of functional foods that promote health beyond providing basic nutrition is on the rise, as food manufacturers increase their offer to consumers' needs. Most functional foods' research has focused on nutritional composition of the food and, to a lesser extent, on the product quality and effects of adding food texture enhancers. Functional ingredients, such as purified bioactive compounds or concentrated extracts from natural sources, can be successfully incorporated into foods, providing novel functional product categories and new commercial opportunities. However, the additional challenge of ensuring that functional ingredients survive, remaining active and bioavailable after food processing and storage, endures. In addition, the appearance and sensory properties of foods are the most important attributes to the consumer, prior to the nutritional value. From a manufacturing point of view, the most popular functional food product should be relatively easy to formulate and process (Day et al., 2009).

It is well established that food components contribute to physiologic and biologic well-being. Functional foods are thought to generate such useful effects as bio-regulation of appetite, biodefence (including immunity and suppression of allergies), prophylaxis against hypertension, diabetes, cancer, hypercholesterolemia, anaemia and platelet aggregation (Mitsuoka, 2014).

\subsection{Biochemistry of functional ingredients}

Multiple modes of action on key targets have been proposed for the beneficial effects of natural bioactive compounds, including antioxidant function and anti-inflammatory functions, modulation of signal transduction and gene expression, leading to the induction of apoptosis and necrosis. The functional compounds naturally present in plants have been proposed to exert their biological action through several mechanisms: i) direct free radical scavenging; ii) downregulation of radical production through elimination of 
radical precursors and metal chelation; iii) inhibition of enzymes involved in reactive oxygen species (ROS) production; iv) elevation and protection of endogenous antioxidants; v) modulation of signal transduction systems and mitochondrial function. In the case of polyphenols, their antioxidant activity is a result of their peroxidation chain breaking ability (Jacob et al., 2012).

Besides lowering the expression of enzymes (e.g., xanthine oxidase) involved in ROS generation, antioxidants might also upregulate the expression of antioxidant enzymes, such as glutathione peroxidase (GPX), catalase (CAT) and superoxide dismutase (SOD) or enhance the synthesis of reduced glutathione (GSH) (Du, Guo, \& Lou, 2007).

Antioxidants have multiple modes of action. Polyphenols containing ortho-dihydroxy groups, for instance, have been found to stimulate the transcription of genes encoding the antioxidant enzymes through the Keap1/Nrf2/ARE pathway, which is a prime target for cancer chemoprevention and a potential target for preventing neurodegenerative diseases and enhancing longevity, since the generation of ROS is a critical initiating factor in these processes. Another mode of action is the modulation of the transcription nuclear erythroid-derived 2-related factor (Nrf2) that controls the expression of several genes associated with cytoprotection, including antioxidant enzymes, xenobiotic-metabolizing enzymes (phase 2 enzymes), metal-chelating enzymes, drug transporters, and molecular chaperones (Hayes, McMahon, Chowdhry, \& Dinkova-Kostova, 2010). In fact, the expression of cytoprotective enzymes, e.g., glutathione-S-transferase (GST) or nicotinamide adenine dinucleotide phosphate-H quinone oxidoreductase (NQO1), is a common feature of cancer-preventive molecules (particularly, diphenols and phenylpropanoids). The efficiency of induction of NQO1 was considered to be linearly correlated with their ability to release an electron in a two-step process: i) oxidation of diphenols into quinones, and ii) oxidation of thiol groups in Keap1 involved in Nrf activation (Jacob et al., 2012).

Other molecules, such as sulphoraphane or curcumin, contain Michael acceptor functionalities (olefin or acetylene structures conjugated to electron withdrawing groups) as well as phenolic hydroxyl groups (with higher efficiency if located in ortho positions) that can scavenge ROS or nitrogen-centered free radicals. This is a key pathway involved in cytoprotection from ROS and inflammation and helps to prevent the development of chronic degenerative diseases (Jacob et al., 2012).

The results obtained in several studies suggest that natural functional ingredients act through multiple mechanisms that enhance their in vivo efficacy. Thus, it is becoming increasingly clear that phytochemicals, including polyphenols, carotenoids, and several others, as well as their physiological metabolites, may exert their beneficial action through multiple functional modes (Williams, Spencer, \& Rice-Evans, 2004).

\subsection{Bioaccessibility and bioavailability of functional ingredients}

Functional ingredients can be absorbed by an active process or through passive diffusion across the membrane. More complex structures have to be broken during digestion, before the active ingredients can be absorbed. The molecular characteristics of nutraceuticals have great influence on their absorption, often explaining their limited uptake and extremely low physiological levels (Lipinski, Lombardo, Dominy, \& Feeney, 2012).

Accordingly, bioavailability of nutrients and bioactive compounds present in plant products is an extremely important area of food and nutrition research. Food and Drug Administration (FDA) defined bioavailability "as the rate and extent to which the active substances contained in a drug are absorbed and become available at the site of action". It is usually measured in the blood plasma and is affected by many factors, including the processing technique, individual variability and physiological state dose. Apart from processing itself, the presence of other food components in the ingredients, also affects the bioavailability of nutrients (Failla, Huo, \& Thakkar, 2008). Accordingly, it is essential to develop predicting in vitro digestion methods that can be useful tools for screening the factors and components that modify the bioavailability of bioactive compounds in a given matrix composition, allowing selecting the formulation conditions that achieve the highest availability (Fernández-García, Mínguez-Mosquera, \& Pérez-Gálvez, 2007).

The concept of bioaccessibility is slightly different, since it corresponds to the amount of an ingredient/nutrient that is available for absorption in the gut after digestion (Hedrén, Mulokozi, \& Svanberg, 2002). In either case, bioaccessibility and bioavailability of a nutrient are determined by the physical properties of the food matrix. Even in natural foods, bioaccessibility of the bioactive compounds that characterize the product may decrease due to other interfering components of the diet (Fernández-García, Rincón, \& Pérez-Gálvez, 2008).

\section{New protected-delivery technologies in functional foods preparation}

The main objective of protected-delivery technologies is preserving the core material from adverse environmental conditions (e.g., light, oxygen, or $\mathrm{pH}$ ), promoting a controlled liberation of the encapsulate, determining the rates of the carried bioactive compounds and, ultimately, how much is absorbed into the body (the overall efficacy of the compounds). These techniques can be applied to reduce the reactivity with the environment, protect the core material from degradation, modify some characteristic to allow easier handling, mask unpleasant flavours or odours, dilute the core material when only a small amount is required, or provide barriers between the sensitive bioactive materials (Anal \& Singh, 2007; Champagne \& Fustier, 2007; Desai \& Park, 2005). Briefly, their major advantage is the ability to control the release rate of the incorporated materials and deliver them to the right place at the right time (Schäfer et al., 1992).

\subsection{Microencapsulation}

Microencapsulation is a process by which a core (i.e., a bioactive or functional ingredient) is packaged within a secondary material to form a microcapsule. This secondary material, known as the encapsulant, matrix or shell, will form a protective coating or matrix around the core, isolating it from its surrounding environment until its release is triggered, avoiding undesirable interactions of the bioactive ingredient with other food components or chemical reactions that could lead to its degradation, possible undesirable consequences on taste and odour, as well as negative health effects (de Vos, Castenmiller, Hamer, \& Brummer, 2006).

Microcapsules are small vesicles semipermeable, spherical, with thin and strong membranes surrounding a solid or liquid core (Anal \& Singh, 2007). Many morphologies can be produced for encapsulation, but two major morphologies are more commonly seen: mononuclear capsules with a single core involved by a shell and the aggregates with many cores embedded in a matrix (Schrooyen, van der Meer, \& De Kruif, 2001).

The design of a microencapsulated ingredient requires knowledge of (1) the core, (2) the encapsulant materials, (3) interactions between the core, matrix and the environment, (4) the stability of the microencapsulated ingredient in storage and when incorporated into the food matrix and (5) the mechanisms that control the release of the core. Despite several ingredients are suitable to be 
encapsulated, the scaling up of the process may be very difficult and processing costs are expensive (Anal \& Singh, 2007; de Vos et al., 2006).

The encapsulant materials can be a pure compound or a mixture (sugars, gums, proteins, natural and modified polysaccharides, lipids and synthetic polymers), which are also called coating material, wall material or capsule membrane (Gibbs, Kermasha, Alli, \& Mulligan, 1999). These materials are generally selected from a range of proteins, carbohydrates, lipids and waxes (Table 4), depending on the properties of the core to be encapsulated and the purpose of microencapsulation. They are typically film forming, pliable, odourless, tasteless and non-hygroscopic. Solubility in aqueous media or other specific solvents and/or ability to exhibit a phase transition (such as melting or gelling) might be useful (Sanguansri \& Augustin, 2010).

Among them, protein-based micro-particles have found wide applications in the food industry, because they can be precisely designed for use in many food formulations and virtually any ingredient can be encapsulated, whether hydrophobic, hydrophilic, or even from microbial origin (Chen et al., 2006).

Carrageenan has also been widely used. This natural polysaccharide, extracted from marine algae, requires a high temperature to be dissolved at concentrations ranging from 2 to $5 \%$ (Klein \& Vorlop, 1985). Alginic acid might also form natural polymers, which are profuse in the cell walls of brown algae. Due to alginate' biocompatibility and simple gelation with divalent cations such as $\mathrm{Ca}^{2+}$, it is widely used for cell immobilization of cultured cells and encapsulation. Cellulose acetate phthalate has also been increasingly used because it is physiologically inert when administered, besides having a wide range of $\mathrm{pH}$ values in which it is soluble (Anal \& Singh, 2007). Another well-known encapsulating polymer is chitosan, which is a linear polysaccharide composed of $\beta-(1-4)$ linked D-glucosamine and $N$-acetyl-D-glucosamine with increasing importance in the food field because of its unique biocompatibility, non-toxicity and biodegradability (Anal \& Stevens, 2005).

The starch that is not digested by pancreatic amylases in the small intestine can also be used to ensure the viability of probiotic populations in the intestine and also offers robustness and resilience to environmental stresses (Crittenden et al., 2001).

Independently of the encapsulating material, the release of the core depends on the formulation used to obtain the desired structure or the accurate size control. Particles may thus consist of a core composed of one to several types of ingredients surrounded by a wall or barrier of uniform or non-uniform thickness either singlelayered or multi-layered. Matrix degradation, and consequently the release of contents, can thus be controlled to occur at different times. Larger particles generally release encapsulated compounds more slowly and over longer periods, while particle size reduction

Table 4

Materials commonly used as encapsulants for food application purposes (Sanguansri \& Augustin, 2010).

\begin{tabular}{lll}
\hline Carbohydrates & Proteins & Lipids and waxes \\
\hline Native starches & Sodium caseinate & Vegetable fats and oils \\
Modified starches & Whey proteins & Hydrogenated fats \\
Resistant starches & Isolated wheat proteins & $\begin{array}{l}\text { Palm stearin } \\
\text { Carnauba wax }\end{array}$ \\
Maltodextrins & Soy proteins & Bees wax \\
Dried glucose syrups & Gelatins & Shellac \\
Gum acacia & Zein & Polyethylene glycol \\
Alginates & Albumin & \\
Pectins & & \\
Carrageenan & & \\
Chitosan & & \\
Cellulosic materials & & \\
Sugars and derivatives & & \\
\hline
\end{tabular}

introduces several bio-adhesive improvement factors, including increased adhesive force and prolonged GI transit time, leading to a higher drug bioavailability (Pothakamury \& Barbosa-Cánovas, 1995).

There are several types of foods functionalized using microencapsulated carriers. According to their share in functional food market, the most relevant examples are i) dairy products, ii) cereal products and healthy bars, iii) beverages (mainly vitamin- and mineral-enriched drinks and weight-control beverages), iv) fats and oil products (particularly, spreads with cholesterol-lowering phytosterols, healthy oils, sauces and dips with nutraceutical ingredients); and v) bakery products (Sanguansri \& Augustin, 2010).

A wide variety of techniques are used for encapsulation. In general, three steps are involved: i) the formation of the wall around the material to be encapsulated; ii) assuring that undesired leakage does not occur; iii) ensuring that unwelcome materials are kept out (Gibbs et al., 1999).

The technologies available to encapsulate active ingredients are usually classified as mechanical (emulsification, spray-drying, fluidised-bed coating, centrifugal extrusion, spinning disks, pressure extrusion and hot-melt extrusion) or chemical (ionotropic gelation, simple or complex coacervation, solvent evaporation, liposome entrapment or cyclodextrin complexation) processes (Augustin \& Hemar, 2009; Champagne \& Fustier, 2007; Sanguansri \& Augustin, 2010).

Some of the presently used technologies include:

i) Spray drying - typically used for the preparation of dry and stable food additives and flavors, this is the most widely used microencapsulation technique, mainly for being economical, flexible and suitable to be performed as a continuous operation. This process is based in the injection of a liquid suspension of the bioactive product at the top of a vessel which dries the droplet into a fine powder particle in conjunction with hot air; the liquid droplet solidifies and entraps the bioactive product (Champagne \& Fustier, 2007). The wall material represents a relative disadvantage of this methodology, since it must be soluble in water; modified starches, maltodextrin or gums are usually used as the wall materials. The produced particles are typically spherical $(10-100 \mu \mathrm{m}$ in diameter) (Fang \& Bhandari, 2010). This technique allows adding multiple coating layers besides providing a high protection to short exposure periods to acids, humidity and oxygen; however, cells are released at slow rates (low temperatures) and the phase separation in coating is lipid-based (Champagne \& Fustier, 2007).

ii) Freeze drying - also called lyophilisation or cryodesiccation, this process is useful for a wide variety of heat-sensitive ingredients (Oetjen \& Haseley, 2008). Encapsulation by freeze drying is achieved when the core materials homogenize in the initial solution and then co-lyophilizes, originating irregular particles. The long dehydration period is commonly seen as a disadvantage, but this technique is suitable to encapsulate water-soluble essences and natural aromas, as well as drugs. Nevertheless, the improvement in the stability or bioactivity of the core materials was sometimes reported as insufficient (Fang \& Bhandari, 2010).

iii) Coacervation - this methodology is based on the phase separation of the hydrocolloids present in an initial solution and the further deposition of the newly formed coacervate around the suspended or emulsified bioactive ingredient (Gouin, 2004). Coacervation encapsulation, particularly when achieved with more than one colloidal solute did not usually allows obtaining particles with definite forms, besides being considered as an expensive method. However, it 
is especially suitable for high-valued and sensitive functional ingredients (e.g., polyphenols). The wall materials are usually composed of gelatins or glucan (Fang \& Bhandari, 2010).

iv) Liposome entrapment - These colloidal particles consist of a lipid membranous system (lipid bilayer) encapsulating a hydrophilic space, which makes them appropriate to encapsulate water-soluble, lipid-soluble, and amphiphilic ingredients. Despite the variety of liposome production techniques, the underlying mechanism is generally the same, being triggered by the hydrophilic-hydrophobic interaction between phospholipids and water. The most relevant advantage of this technique is the possibility of controlling the release rate and exact point of delivery of the incorporated materials (Fang \& Bhandari, 2010). Bioactive agents encapsulated into liposomes are protected from the digestion in stomach, promoting their bioavailability and bioactivity. The nature of the core material affects the efficiency of liposome encapsulation, which can be promoted by adding ethanol to the preparation solution (Fang, Lee, Shen, \& Huang, 2006).

v) Cocrystallization - in this process, the structure of sucrose (in the form of a supersaturated syrup) is modified $\left(120^{\circ} \mathrm{C}\right.$, 95-97 ${ }^{\circ}$ Brix) from a perfect to an irregular agglomerated crystal. If a bioactive ingredient is added before this spontaneous crystallization, it will be incorporated in the void spaces of the porous matrix of the newly formed microsized crystals (Chen et al., 2006). Besides improving the solubility, homogeneity, dispersibility, hydration, anticaking, stability and flowability of the encapsulated materials, this technique allows converting liquid materials into powders, which might convey benefits for applications in the pharmaceutical industry (Fang \& Bhandari, 2010).

vi) Yeast-encapsulation - this approach uses yeast cells (Saccharomyces cerevisiae) as the encapsulating material, being usually applied to essential oils, flavours and polyphenols. The core ingredients must be able to pass freely across the cell wall and passively remain inside the cells. The yeast cells are also expected to be able of controlling the diffusion of the incorporated ingredients, using a preselected temperature and time, while the cell wall should prevent the evaporation, extrusion and oxidation of the core material. This technique is entangled with green chemistry principles, as it uses no additives besides water, yeast and core ingredients. Furthermore, it has a low cost and allows processing high volumes of bioactive ingredients (Blanquet et al., 2005).

vii) Cold gelation - this recent method provides an alternative way to develop protein micro particles in the food industry. No organic solvents are required for this method, and encapsulation is achieved under mild conditions, thereby minimizing destruction of sensitive nutraceutical compounds. More importantly, globular proteins (e.g., whey proteins) have the ability to denature, dissociate, and aggregate under different conditions of $\mathrm{pH}$, ionic strength, and temperature (Champagne \& Fustier, 2007).

Several efforts are also being directed to integrate molecules of interest in hydrogels. A hydrogel is a water-swollen network of hydrophilic polymers that can swell in water and hold a large amount of water, while maintaining a network structure (Qiu \& Park, 2012). These particles are known for their functionality and ability to tune physical properties in industrial applications such as controlled drug delivery, cosmetics, pharmaceuticals and foods (Çam, Içyer, \& Erdoğan, 2014; Caleja et al., 2015; Stokes, 2011; Tan, Tam, Lam, \& Tan, 2005). Although successful as oral drug delivery systems, one of the limitations of these hydrogels for food applications is their high content in components not generally recognized as safe for regular consumption. Hence, there is a tendency towards using food proteins to develop environment sensitive hydrogels to deliver nutraceuticals. In fact, the exposure of multiple functional groups within the protein upon denaturing might be exploited to create different interactions between nutraceutical compounds and polypeptide chains. The ability of hydrogels made from proteins to entrap both fat-soluble and water-soluble food components should also contribute to the development of innovative functional solid foods (Chen et al., 2006).

A fundamental advantage of the hydrogels is that nutraceutical carrier gels can stabilize food texture, which is a highly desirable characteristic in the manufacturing of food products (Shewan \& Stokes, 2013). In fact, we can refer to various advantages of micro-hydrogels suspensions: their capacity to modify their own volume in response to changes in solvent quality and properties (Stokes, 2011); the possibility to remove harmful volatile organic compounds; enabling fat reduction; decreasing energy density of foods (Sagis et al., 2008); reducing sedimentation during transport and storage; or stabilising emulsion droplets (Hedges, 2012). Since micro-hydrogel particles possess a colloidal state, it allows them to be designed to have long-range attractive forces, which can cause aggregation and flocculation using a small volume. Furthermore, the volume of the micro-hydrogel suspension might be increased, either by adding a high percentage of micro-hydrogels, as well as inducing swelling by a change in the $\mathrm{pH}$ or in the solvent (Shewan \& Stokes, 2013). Also, the micro-hydrogel suspensions do not possess the non-linear viscoelasticity typical from other polymer solutions, offering an alternative to obtain desired shear thinning and yield stresses without undesirable elastic properties (Stokes, 2011).

Moreover, the presence of acidic and basic groups in polypeptide chains allows modulating the release rate of molecules from protein gels according to $\mathrm{pH}$ variations (Qiu \& Park, 2012).

There are several methods of manufacturing micro-hydrogels and the suitability depends on the hydrocolloid or polymer carrier as well as the functionality and particle size distribution. There are three major techniques to manufacture micro-hydrogels: i) monomer; ii) polymer; iii) macro-gel. For synthetic microhydrogels the starting point is usually a monomer, while for biopolymer micro-hydrogels it is usually the polymer or macro-gel (Shewan \& Stokes, 2013).

\subsection{Nanoencapsulation}

The techniques used for nanoencapsulation are more complex than for microencapsulation, mainly due to the intricate morphology of the capsule and core material and the demand in controlling the release rate of the nanoencapsulates. Nanoencapsulation involves the incorporation, absorption or dispersion of bioactive compounds and the formation of functional materials encapsulated in small vesicles at a length scale of less than $100 \mathrm{~nm}$ (Reis, Neufeld, Ribeiro, \& Veiga, 2006). Nanoparticles provide a greater surface area and increased solubility, enhancing bioavailability due to their subcellular size and improved controlled release (Mozafari et al., 2008). They can extend the compound' residence time in the GI tract by decreasing the influence of intestinal clearance mechanisms and increasing the surface available to interact with the biological support (Arbós, Arangoa, Campanero, \& Irache, 2002; Brannon-Peppas, 1995). They can also penetrate deeply into tissues through fine capillaries, cross the epithelial lining fenestration (e.g., in the liver) and are generally taken up efficiently by cells (Desai, Labhasetwar, Amidon, \& Levy, 1996), thus allowing efficient delivery of active compounds to target sites in the body. 
Protein-based nanoparticles are particularly interesting because they are relatively easy to prepare and their size distribution can be monitored to increase the circulation time in the GI tract. Protein nanoparticles could be internalized by cells and degraded to release the nutraceutical content, significantly improving bioavailability while avoiding undesired toxic side effects of the free compound (Li, Jiang, Xu, \& Gu, 2015).

Two strategic approaches are currently used to produce nanoparticles: i) top down approach that involves the application of precise tools in which big structures are contracted by breaking up bulk materials, allowing the size reduction and shaping of the structure for the desired application with energy input; ii) bottom up approach, which allows structures to be built from small molecules that are capable of self-assembly and self-organization and aggregation to form nanoparticles. These nanoencapsulation techniques can be used for encapsulation of various hydrophilic and lipophilic bioactive compounds (Augustin \& Sanguansri, 2009).

Nanoparticles can interact with the components by hydrogen bonds and hydrophobic interactions (Li et al., 2015), being settled with hydrophobic groups inside and polar groups on surface of particles, which allow them to remain stable due to their interparticle repulsions and hydration (Li et al., 2015).

There is a number of mechanisms that allow the control of the size and characteristics of nanoparticles. Dynamic light scattering (DLS) and electron microscopy (EM) are some of those techniques. DLS evaluates the particle size and size distribution, while EM measures size and morphology of dry particles (Bootz, Vogel, Schubert, \& Kreuter, 2004).

Cyclodextrins (CDs) are extensively used as additives to increase the solubility of poorly water-soluble organic compounds by the formation of an inclusion complex (Chakraborty, Basu, \& Basak, 2014). This family of cyclic oligomers compounds might be produced from the transformation of starch by enzymatic conversion (Jeang, Lin, \& Hsieh, 2005). CDs are empty capsules of sugar molecules bound together in a ring with six, seven or eight glucose residues that can include a great variety of molecules in its cavity; the external part is hydrophilic and the internal is hydrophobic (Astray, Gonzalez-Barreiro, Mejuto, Rial-Otero, \& Simal-Gándara, 2009). Some years ago, CDs were considered poisonous substances. However, nowadays we know that they are not only nontoxic, but they are also used in food and can be helpful for protecting flavours, vitamins and natural colours. In fact, CDs have been used as additives such as solubilizers, to stabilize flavours and fragrances, to eliminate undesired tastes, to improve the physical and chemical properties or to enhance the bioavailability of poorly soluble drugs (Del Valle, 2004). Once again, the core material influences the effectiveness of the technique. Here, the higher the hydrophobicity and the smaller the molecule, the greater the affinity for CDs (Fang \& Bhandari, 2010).

The production of CDs is divided into four steps: $i)$ the culture of the microorganism that produce the cyclodextrin glucosyl transferase enzyme, separation, concentration and purification of the enzyme from the fermentation environment; ii) the enzymatic conversion of pre-hydrolysed starch in mixture of dextrins followed by separation of CDs from the mixture; iii) purification and iv) crystallization (Astray et al., 2009; Mazzobre, Elizalde, dos Santos, Ponce Cevallos, \& Buera, 2010)). The purification of $\alpha$ - and $\gamma$-CDs increases considerably the cost of production; so, for economic reasons, $97 \%$ of the CDs used in market are $\beta$-CDs, and this isomer has the lowest water solubility of all CDs (Astray et al., 2009).

Flavour plays an important role in the satisfaction of the consumer and several times the manufacturing and storage process of materials and ingredients cause modifications in flavour by reducing aroma compound intensity or producing off-flavour components (Astray et al., 2009). The addition of $\beta$-CDs as stabilizing or thickening agents could retain some aroma compounds in food matrices during thermal processes (Jouquand, Ducruet, \& Giampaoli, 2004). In fact, of all encapsulating techniques, molecular encapsulation of flavours with $\beta$-CDs is the most effective for providing protection against heat and evaporation. Overall, CDs reduce residual organic volatile contaminants in packaging materials, improve barrier properties of the package materials, improve sensory properties and maintain food quality and safety (Astray et al., 2009).

The high suitability of $\beta$-CDs is clearly emphasised by the diversity of food products already functionalized using this technique. Some of the most well-known include fruit juices, wheat flour, low-cholesterol cheese, low-cholesterol butter, lowcholesterol eggs, beer, chocolate, tea and seed oils (Mazzobre et al., 2010).

\subsection{Emulsions}

An emulsion is a mixture of at least two immiscible liquids, usually oil and water, where one of the liquids is dispersed as small spherical droplets in the other. Emulsions are turbid, with droplet sizes ranging from 0.2 to $10 \mu \mathrm{m}$ and may remain stable for a considerable period of time, despite being, in general, thermodynamically unstable systems (Anton, Benoit, \& Saulnier, 2008). Emulsion technique is applied to bioactive compounds in aqueous solutions to stabilize the interfacial layer between the dispersed and continuous phase which has been created by adding energy to the system (Flanagan \& Singh, 2006).

Emulsions can be classified according to the spatial organization of the oil and water phases: i) oil/water emulsion when oil droplets are dispersed in an aqueous phase; ii) water/oil emulsion when the water droplets are dispersed in an oil phase; iii) several other mixtures between the previous (Benichou, Aserin, \& Garti, 2004).

Microemulsions are systems comprising a mixture of water, hydrocarbons and amphiphilic compounds which form kinetically and thermodynamically stable compounds, transparent, homogeneous and isotropic solutions with particle sizes ranging from 5 to 100 nm (Paul \& Moulik, 1997). Some of the macroscopic characteristics that should be controlled include viscosity, conductivity and dielectric measurements (Mackeben, Müller, \& MüllerGoymann, 2001). Microemulsions are formed from the spontaneous self-assembly of the hydrophobic and hydrophilic components of surfactant molecules, having numerous applications in pharmacy, cosmetics and in foods (Flook, Cameron, \& Wren, 2004). However, in foods, the use of microemulsions is limited by the types of surfactants which are used to facilitate microemulsions formation, because many surfactants are not permitted in foods (Flanagan \& Singh, 2006).

Nanoemulsions, also known as fine dispersed emulsions and submicron emulsions, are not as thermodynamically stable as in the case of microemulsions (Tadros, Izquierdo, Esquena, \& Solans, 2004). They are produced by microfluidization or micelle formation techniques (Champagne \& Fustier, 2007) and exhibit poor solubility and low bioavailability (Flanagan \& Singh, 2006). The mechanical processes that generate nanomeric emulsions include the drop creation, the deformation and disruption of macrometric initial droplets, followed by the surfactant adsorption at their interface to insure the steric stabilization (Anton et al., 2008). The main particularity of nanoemulsions, making them prime candidates for nanoparticle engineering, is the great stability of the droplet suspension (Anton et al., 2008).

The industrial application of emulsions is increasing. "Functional emulsions" is an US patent name for polyphenols dissolved in ethanol, which are then moved with vegetable oil in a homogenizer 
and are used in pharmaceutical and nutraceutical industries (Nakajima Nabetani, Ichikawa, \& Xu, 2003).

The main products functionalized with emulsions as incorporation carriers include milk, yogurt, vegetable oils, mayonnaise, fruit juices and ice cream (Fustier, Taherian, \& Ramaswamy, 2010).

\section{Conclusions}

The beginning of the third millennium is being characterized by an increasing life expectancy and a great coverage of health-related issues by the media. Generally, consumers are more interested in new food products, whose functions go beyond the nutritional and sensory role, having also potential benefits over the physiological functions, ultimately controlling and preventing diseases. In this context, overall preferences are moving towards products that are capable of producing metabolic and physiological effects, ensuring health and wellbeing by restoring the balance of intestinal flora, counteracting the oxidative stress or stimulating the immune response. Considering the present marketing demands and technological obstacles to overcome, the future development of functional foods will probably include: i) improving the solubility of lipophilic compounds in high moisture beverages; ii) stabilising sensitive compounds such as vitamins, flavors, essential oils or unsaturated fatty acids; iii) preserving the physical characteristics of a foodstuff under stress conditions like freezing, thawing, microwaving, blanching, or pasteurising; iv) prevent oxidation processes.

A well-accepted fact is that the effectiveness of nutraceutical products depends on the maintenance of the stability, bioactivity and bioavailability of their active ingredients. Thereby, the delivery of these agents requires food formulations and production processes able to maintain the active molecular structures until their consumption and release in the physiological target. Accordingly, besides developing more effective methods of extraction and characterization of the properties of functional foods, it is imperative to include protective methodologies (microencapsulation, nanoencapsulation and emulsions), before incorporating bioactive ingredients into functional foods. As previously explained, independently of the encapsulating material, the release of the core ingredient will depend on the formulation used to obtain the aimed structure or the accurate size.

The development of novel foodstuffs is particularly challenging, because the cornerstone aspects of product safety, preparation mode and sensory quality, cannot be hampered by the incorporated bioactive compounds. In addition, besides selecting the bioactive molecule, it is essential to assure a suitable delivery profile, considering biodegradability and biocompatibility concerns. In fact, there is not an ideal delivery system, since each of the available ones has its advantages and limitations. Even so, some transversal principles should be considered in the design of innovative food products: i) checking regulatory issues for the permission of using the bioactive molecule and encapsulating material; ii) knowing the physical state in which the product should be prepared; iii) taking into account the conditions it must undergo throughout its processing, storage and consumption; iv) defining the moment and form by which it should be added during the production process; v) anticipating possible interactions with other food ingredients.

Another important consideration to bear in mind is the need to adopt a multidisciplinary approach. In fact, when the theme is food, we can never forget that the accurate knowledge of the food microstructure and how it might improve consumers' health should always go along with a high level of creativity and tastefulness. This is undoubtedly the right way to achieve successful outcomes.

\section{Acknowledgments}

João C.M. Barreira is grateful to Fundação para a Ciência e a Tecnologia (FCT) for his post-doctoral research grant (SFRH/BPD/ 72802/2010), financed by POPH-QREN and subsidized by FSE and MCTES. This work received financial support from the European Union (FEDER funds through COMPETE) and National Funds (FCT) through project Pest-C/EQB/LA0006/2013. The work also received financial support from the European Union (FEDER funds) under the framework of QREN through Project NORTE-07-0124 FEDER000069.

\section{References}

Anal, A. K., \& Singh, H. (2007). Recent advances in microencapsulation of probiotics for industrial applications and targeted delivery. Trends in Food Science \& Technology, 18, 240-251.

Anal, A. K., \& Stevens, W. F. (2005). Chitosan-alginate multilayer beads for controlled release of ampicillin. International Journal of Pharmaceutics, 290, 45-54.

Anton, N., Benoit, J. P., \& Saulnier, P. (2008). Design and production of nanoparticles formulated from nano-emulsion templates - a review. Journal of Controlled Release, 128, 185-199.

Arbós, P., Arangoa, M. A., Campanero, M. A., \& Irache, J. M. (2002). Quantification of the bioadhesive properties of protein-coated PVM/MA nanoparticles. International Journal of Pharmaceutics, 242, 129-136.

Arceusz, A., Wesolowski, M., \& Konieczynski, P. (2013). Methods for extraction and determination of phenolic acids in medicinal plants: a review. Natural Product Communications, 8, 1821-1829.

Astray, G., Gonzalez-Barreiro, C., Mejuto, J. C., Rial-Otero, R., \& Simal-Gándara, J (2009). A review on the use of cyclodextrins in foods. Food Hydrocolloids, 23 $1631-1640$.

Augustin, M. A., \& Hemar, Y. (2009). Nano- and micro-structured assemblies for encapsulation of food ingredients. Chemical Society Reviews, 38, 902-912.

Augustin, M. A., \& Sanguansri, P. (2009). Nanostructured materials in the food industry. Advances in Food and Nutrition Research, 58, 183-213.

Azmir, J., Zaidul, I. S. M., Rahman, M. M., Sharif, K. M., Mohamed, A., Sahena, F., et al. (2013). Techniques for extraction of bioactive compounds from plant materials: review. Journal of Food Engineering, 117, 426-436.

Barreira, J. C. M., \& Ferreira, I. C. F. R. (2015). Steroids in natural matrices: chemical features and bioactive properties. In V. K. Gupta, \& M. G. Tuohy (Eds.), Biotechnology of bioactive compounds: Sources and applications (pp. 395-432). John Wiley \& Sons, Ltd.

Benichou, A., Aserin, A., \& Garti, N. (2004). Double emulsions stabilized with hybrids of natural polymers for entrapment and slow release of active matters. Advances in Colloid and Interface Science, 108-109, 29-41.

Bernhoft, A. (2010). A brief review on bioactive compounds in plants. The Norwegian Academy of Science and Letters. Oslo: Norway.

Birt, D. F., Hendrich, S., \& Wang, W. (2001). Dietary agents in cancer prevention: flavonoids and isoflavonoids. Pharmacology \& Therapeutics, 90, 157-177.

Blanquet, S., Garrait, G., Beyssac, E., Perrier, C., Denis, S., Hébrard, G., et al. (2005). Effects of cryoprotectants on the viability and activity of freeze dried recombinant yeasts as novel oral drug delivery systems assessed by an artificial digestive system. European Journal of Pharmaceutics and Biopharmaceutics, 61, $32-39$.

Bootz, A., Vogel, V., Schubert, D., \& Kreuter, J. (2004). Comparison of scanning electron microscopy, dynamic light scattering and analytical ultracentrifugation for the sizing of poly (butyl cyanoacrylate) nanoparticles. European Journal of Pharmaceutics and Biopharmaceutics, 57, 369-375.

Brannon-Peppas, L. (1995). Recent advances on the use of biodegradable microparticles and nanoparticles in controlled drug delivery. International Journal of Pharmaceutics, 116, 1-9.

Bravo, L. (1998). Polyphenols: chemistry, dietary sources, metabolism, and nutritional significance. Nutrition Reviews, 56, 317-333.

Caleja, C., Barros, L., António, A. L., Cirić, A., Barreira, J. C. M., Soković, M., et al. (2015). Development of a functional dairy food: exploring bioactive and preservation effects of chamomile (Matricaria recutita L.). Journal of Functional Foods, $16,114-124$.

Çam, M., Içyer, N. C., \& Erdoğan, F. (2014). Pomegranate peel phenolics: microencapsulation, storage stability and potential ingredient for functional food development. LWT - Food Science and Technology, 55, 117-123.

Chakraborty, S., Basu, S., \& Basak, S. (2014). Effect of $\beta$-cyclodextrin on the molecular properties of myricetin upon nano-encapsulation: insight from optical spectroscopy and quantum chemical studies. Carbohydrate Polymers, 99, 116-125.

Champagne, C. P., \& Fustier, P. (2007). Microencapsulation for the improved delivery of bioactive compounds into foods. Current Opinion in Biotechnology, 18 184-190.

Chen, L., Remondetto, G. E., \& Subirade, M. (2006). Food protein-based materials as nutraceutical delivery systems. Trends in Food Science \& Technology, 17, $272-283$. 
Chester, T., Pinkston, J., \& Raynie, D. (1996). Supercritical fluid chromatography and extraction. Analytical Chemistry, 68, 487-514.

Chung, K. T., Wong, T. Y., Wei, C. I., Huang, Y. W., \& Lin, Y. (1998). Tannins and human health: a review. Critical Reviews in Food Science and Nutrition, 38, 421-464.

Crittenden, R., Laitila, A., Forssell, P., Mättö, J., Saarela, M., Mattila-Sandholm, T., et al. (2001). Adhesion of bifidobacteria to granular starch and its implications in probiotic technologies. Applied and Environmental Microbiology, 67, 3469-3475.

Day, L., Seymour, R. B., Pitts, K. F., Konczak, I., \& Lundin, L. (2009). Incorporation of functional ingredients into foods. Trends in Food Science \& Technology, 20, 388-395.

Del Valle, E. M. (2004). Cyclodextrins and their uses: a review. Process Biochemistry, 39, 1033-1046.

Desai, M., Labhasetwar, V., Amidon, G., \& Levy, R. (1996). Gastrointestinal uptake of biodegradable microparticles: effect of particle size. Pharmaceutical Research, 13, 1838-1845.

Desai, K. G. H., \& Park, H. J. (2005). Recent developments in microencapsulation of food ingredients. Drying Technology, 23, 1361-1394.

Desmond, C., Corcoran, B., Coakley, M., Fitzgerald, G., Ross, R., \& Stanton, C. (2005) Development of dairy-based functional foods containing probiotics and prebiotics. Australian Journal of Dairy Technology, 60, 121-126.

Dicko, M. H., Gruppen, H., Traoré, A. S., Voragen, A. G. J., \& van Berkel, W. J. H. (2006) Phenolic compounds and related enzymes as determinants of sorghum for food use. Biotechnology and Molecular Biology Review, 1, 21-38.

Doyon, M., \& Labrecque, J. (2008). Functional foods: a conceptual definition. British Food Journal, 110, 1133-1149.

Du, Y., Guo, H., \& Lou, H. (2007). Grape seed polyphenols protect cardiac cells from apoptosis via induction of endogenous antioxidant enzymes. Journal of Agricultural and Food Chemistry, 55, 1695-1701.

Elliott, R., \& Ong, T. J. (2002). Nutritional genomics. British Medical Journal, 324 $1438-1442$.

Failla, M. L., Huo, T., \& Thakkar, S. K. (2008). In vitro screening of relative bioaccessibility of carotenoids from foods. Asia Pacific Journal of Clinical Nutrition, 17, 200-203.

Fang, Z., \& Bhandari, B. (2010). Encapsulation of polyphenols - a review. Trends in Food Science \& Technology, 21, 510-523.

Fang, J.-Y., Lee, W.-R., Shen, S.-C., \& Huang, Y.-L. (2006). Effect of liposome encapsulation of tea catechins on their accumulation in basal cell carcinomas. Journa of Dermatological Science, 42, 101-109.

Fernández-García, E., Mínguez-Mosquera, M. I., \& Pérez-Gálvez, A. (2007). Changes in composition of the lipid matrix produce a differential incorporation of carotenoids in micelles. Interaction effect of cholesterol and oil. Innovative Food Science \& Emerging Technologies, 8, 379-384.

Fernández-García, E., Rincón, F., \& Pérez-Gálvez, A. (2008). Developing an emulsifier system to improve the bioaccessibility of carotenoids. Journal of Agricultural and Food Chemistry, 56, 10384-10390.

Flanagan, J., \& Singh, H. (2006). Microemulsions: a potential delivery system for bioactives in food. Critical Reviews in Food Science and Nutrition, 46, 221-237.

Flook, K. J. Cameron, N. R., \& Wren, S. A. (2004). Polymerised bicontinuous microemulsions as stationary phases for capillary electrochromatography: effect of pore size on chromatographic performance. Journal of Chromatography A 1044, 245-252.

Fustier, P., Taherian, A. R., \& Ramaswamy, H. S. (2010). Emulsion delivery systems for functional foods. In J. Smith, \& E. Charter (Eds.), Functional food product development (pp. 79-97). John Wiley \& Sons, Ltd.

Giada, M. L. R. (2013). Food phenolic compounds: main classes, sources and their antioxidant power. In J. A. M. González (Ed.), Oxidative stress and chronic degenerative diseases - A role for antioxidants (pp. 87-112). In Tech.

Gibbs, B. F., Kermasha, S., Alli, I., \& Mulligan, C. N. (1999). Encapsulation in the food industry: a review. International Journal of Food Sciences and Nutrition, 50, $213-224$

Gismondo, M., Drago, L., \& Lombardi, A. (1999). Review of probiotics available to modify gastrointestinal flora. International Journal of Antimicrobial Agents, 12 $287-292$.

Gouin, S. (2004). Microencapsulation: industrial appraisal of existing technologies and trends. Trends in Food Science \& Technology, 15, 330-347.

Govender, M., Choonara, Y. E., Kumar, P., du Toit, L. C., van Vuuren, S., \& Pillay, V. (2014). A review of the advancements in probiotic delivery: conventional vs non-conventional formulations for intestinal flora supplementation. AAPS PharmSciTech, 15, 29-43.

Gurib-Fakim, A. (2006). Medicinal plants: traditions of yesterday and drugs of tomorrow. Molecular Aspects of Medicine, 27, 1-93.

Hayes, J. D., McMahon, M., Chowdhry, S., \& Dinkova-Kostova, A. T. (2010). Cance chemoprevention mechanisms mediated through the Keap1-Nrf2 pathway. Antioxidants \& Redox Signaling, 13, 1713-1748.

Hedges, N. D. (2012). Particle stabilised emulsion composition, Patent $\mathrm{N}^{\circ}$ US 8236332 B2.

Hedrén, E., Mulokozi, G., \& Svanberg, U. (2002). In vitro accessibility of carotenes from green leafy vegetables cooked with sunflower oil or red palm oil. Inter national Journal of Food Sciences and Nutrition, 53, 445-453.

Hernández, Y., Lobo, M. G., \& González, M. (2009). Factors affecting sample extraction in the liquid chromatographic determination of organic acids in papaya and pineapple. Food Chemistry, 114, 734-741.

ILSI - International Life Sciences Institute, North America Technical Committee on Food Components for Health Promotion. (1999). Safety assessment and potential health benefits of food components based on selected scientific criteria.
Critical Reviews in Food Science and Nutrition, 39, 203-316.

Jacob, J. K., Tiwari, K., Correa-Betanzo, J., Misran, J., Chandrasekaran, R., \& Paliyath, G. (2012). Biochemical basis for functional ingredient design from fruits. Annual Review of Food Science and Technology, 3, 79-104.

Jäpelt, R. B., \& Jakobsen, J. (2016). Analysis of vitamin K1 in fruits and vegetables using accelerated solvent extraction and liquid chromatography tandem mass spectrometry with atmospheric pressure chemical ionization. Food Chemistry, 192, 402-408.

Jeang, C.-L., Lin, D.-G., \& Hsieh, S.-H. (2005). Characterization of cyclodextrin glycosyltransferase of the same gene expressed from Bacillus macerans, Bacillus subtilis, and Escherichia coli. Journal of Agricultural and Food Chemistry, 53, 6301-6304.

Jones, P. J. H., \& AbuMweis, S. S. (2009). Phytosterols as functional food ingredients: linkages to cardiovascular disease and cancer. Current Opinion in Clinical Nutrition and Metabolic Care, 12, 147-151.

Jouquand, C., Ducruet, V., \& Giampaoli, P. (2004). Partition coefficients of aroma compounds in polysaccharide solutions by the phase ratio variation method. Food Chemistry, 85, 467-474.

Kalliomäki, M., Salminen, S., Poussa, T., Arvilommi, H., \& Isolauri, E. (2003). Probiotics and prevention of atopic disease: 4-year follow-up of a randomised placebo-controlled trial. The Lancet, 361, 1869-1871.

Karaaslan, M., Ozden, M., Vardin, H., \& Turkoglu, H. (2011). Phenolic fortification of yogurt using grape and callus extracts. LWT - Food Science and Technology, 44, 1065-1072.

Klein, J., \& Vorlop, K. (1985). Immobilization technique-cells. In M. Moo-Young (Ed.), Comprehensive biotechnology: The principles, applications, and regulations of biotechnology in industry, agriculture, and medicine (pp. 203-224). Pergamon Press.

Kumar, S., \& Pandey, A. K. (2013). Chemistry and biological activities of flavonoids: an overview. Scientific World Journal, 2013. ID 162750.

Leonard, N. B. (2000). Stability testing of nutraceuticals and functional foods. Handbook of Nutraceuticals and Functional Foods. CRC Press.

Li, Z., Jiang, H., Xu, C., \& Gu, L. (2015). A review: using nanoparticles to enhance absorption and bioavailability of phenolic phytochemicals. Food Hydrocolloids, 43, 153-164.

Lipinski, C. A., Lombardo, F., Dominy, B. W., \& Feeney, P. J. (2012). Experimental and computational approaches to estimate solubility and permeability in drug discovery and development settings. Advanced Drug Delivery Reviews, 64, 4-17.

Mackeben, S., Müller, M., \& Müller-Goymann, C. C. (2001). The influence of water on phase transitions of a drug-loaded reverse micellar solution into lamellar liquid crystals. Colloids and Surfaces A: Physicochemical and Engineering Aspects, 183, 699-713.

Mazzobre, M. F., Elizalde, B. E., dos Santos, C., Ponce Cevallos, P. A., \& Buera, M. P. (2010). Nanoencapsulation of food ingredients in cyclodextrins: effect of water interactions and ligand structure. In J. Smith, \& E. Charter (Eds.), Functional food product development (pp. 24-38). John Wiley \& Sons, Ltd.

Mitsuoka, T. (2014). Development of functional foods. Bioscience of Microbiota, Food and Health, 33, 117-128.

Moreau, R. A., Whitaker, B. D., \& Hicks, K. B. (2002). Phytosterols, phytostanols, and their conjugates in foods: structural diversity, quantitative analysis, and healthpromoting uses. Progress in Lipid Research, 41, 457-500.

Morton, L. W., Caccetta, R. A.-A., Puddey, I. B., \& Croft, K. D. (2000). Chemistry and biological effects of dietary phenolic compounds: relevance to cardiovascular disease. Clinical and Experimental Pharmacology \& Physiology, 27, 152-159.

Mozafari, M. R., Khosravi-Darani, K., Borazan, G. G., Cui, J., Pardakhty, A., \& Yurdugul, S. (2008). Encapsulation of food ingredients using nanoliposome technology. International Journal of Food Properties, 11, 833-844.

Nakajima, M., Nabetani, H., Ichikawa, S., \& Xu, Q. Y. (2003). Functional emulsions. US Patent 6,538,019.

Nayak, B., Dahmoune, F., Moussi, K., Remini, H., Dairi, S., Aoun, O., et al. (2015). Comparison of microwave, ultrasound and accelerated-assisted solvent extraction for recovery of polyphenols from Citrus sinensis peels. Food Chemistry, 187, 507-516.

Oetjen, G.-W., \& Haseley, P. (2008). Freeze-drying. Wiley Online Library.

Okuda, T., Yoshida, \& Hatano, T. (1995). Hydrolyzable tannins and related polyphenols. Progress in the Chemistry of Organic Natural Products, 66, 1-117.

Panigrahi, A., Kiron, V., Satoh, S., Hirono, I., Kobayashi, T., Sugita, H., et al. (2007). Immune modulation and expression of cytokine genes in rainbow trout Oncorhynchus mykiss upon probiotic feeding. Developmental \& Comparative Immunology, 31, 372-382.

Paul, B. K., \& Moulik, S. P. (1997). Microemulsions: an overview. Journal of Dispersion Science and Technology, 18, 301-367.

Pothakamury, U. R., \& Barbosa-Cánovas, G. V. (1995). Fundamental aspects of controlled release in foods. Trends in Food Science \& Technology, 6, 397-406.

Qiu, Y., \& Park, K. (2012). Environment-sensitive hydrogels for drug delivery. Advanced Drug Delivery Reviews, 64, 49-60.

Reis, C. P., Neufeld, R. J., Ribeiro, A. J., \& Veiga, F. (2006). Nanoencapsulation I. Methods for preparation of drug-loaded polymeric nanoparticles. Nanomedicine: Nanotechnology, Biology and Medicine, 2, 8-21.

Sagis, L. M., de Ruiter, R., Miranda, F. J. R., de Ruiter, J., Schroën, K., van Aelst, A. C., et al. (2008). Polymer microcapsules with a fiber-reinforced nanocomposite shell. Langmuir, 24, 1608-1612.

Saha, S., Walia, S., Kundu, A., Sharma, K., \& Paul, R. K. (2015). Optimal extraction and fingerprinting of carotenoids by accelerated solvent extraction and liquid chromatography with tandem mass spectrometry. Food Chemistry, 177, 
$369-375$.

Sánchez-Moreno, C. (2002). Compuestos polifenólicos: estructura y classificación: presencia en alimentos y consumo: biodisponibilidad y metabolismo. Alimentaria, 329, 19-28.

Sanguansri, L., \& Augustin, M. A. (2010). Microencapsulation in functional food product development. In J. Smith, \& E. Charter (Eds.), Functional food product development (pp. 3-23). Blackwell Publishing Ltd.

Scalbert, A., \& Williamson, G. (2000). Dietary intake and bioavailability of polyphenols. Journal of Nutrition, 130(8), 2073s-2085s.

Schäfer, V., von Briesen, H., Andreesen, R., Steffan, A.-M., Royer, C., Tröster, S., et al. (1992). Phagocytosis of nanoparticles by human immunodeficiency virus (HIV)infected macrophages: a possibility for antiviral drug targeting. Pharmaceutical Research, 9, 541-546.

Schrooyen, P. M., van der Meer, R., \& De Kruif, C. G. (2001). Microencapsulation: its application in nutrition. The Proceedings of the Nutrition Society, 60, 475-479.

Shewan, H. M. \& Stokes, J. R. (2013). Review of techniques to manufacture microhydrogel particles for the food industry and their applications. Journal of Food Engineering, 119, 781-792.

de Smet, E., Mensink, R. P., \& Plat, J. (2012). Effects of plant sterols and stanols on intestinal cholesterol metabolism: suggested mechanisms from past to present. Molecular Nutrition Food \& Research, 56, 1058-1072.

Srinivas, K., \& King, J. W. (2010). Supercritical carbon dioxide and subcritical water: complementary agents in the processing of functional foods. In J. Smith, \& E. Charter (Eds.), Functional food product development (pp. 39-78). John Wiley \& Sons, Ltd.

Stafford, H. A. (1983). Enzymic regulation of procyanidin biosynthesis; lack of a flav3-en-3-ol intermediate. Phytochemistry, 11, 2643-2646.
Stokes, J. R. (2011). Rheology of industrially relevant microgels. In A. FernandezNieves, H. M. Wyss, J. Mattsson, \& D. A. Weitz (Eds.), Microgel suspensions: fundamentals and applications (pp. 327-353). Weinheim, Germany: Wiley-VCH Verlag GmbH \& Co. KGaA.

Tadros, T., Izquierdo, P., Esquena, J., \& Solans, C. (2004). Formation and stability of nano-emulsions. Advances in Colloid and Interface Science, 108, 303-318.

Tan, B. H., Tam, K. C., Lam, Y. C., \& Tan, C. B. (2005). Microstructure and rheology of stimuli-responsive microgel systems - effect of cross-linked density. Advances in Colloid and Interface Science, 113, 111-120.

Vilkhu, K., Mawson, E., Simons, L., \& Bates, D. (2008). Applications and opportunities for ultrasound assisted extraction in the food industry - a review. Innovative Food Science and Emerging Technologies, 9, 161-169.

Villares, A., García-Lafuente, A., Guillamón, E., \& Ramos, A. (2012). Identification and quantification of ergosterol and phenolic compounds occurring in Tuber spp. truffles. Journal of Food Composition and Analysis, 26, 177-182.

de Vos, W. M. Castenmiller, J. J. M. Hamer, R. J., \& Brummer, R. J. M. (2006). Nutridynamics - studying the dynamics of food components in products and in the consumers. Current Opinion in Biotechnology, 17, 217-225.

Williams, R. J., Spencer, J. P., \& Rice-Evans, C. (2004). Flavonoids: antioxidants or signalling molecules? Free Radical Biology and Medicine, 36, 838-849.

Wu, C., Wang, F., Liu, J., Zou, Y., \& Chen, X. (2015). A comparison of volatile fractions obtained from Lonicera macranthoides via different extraction processes: ultrasound, microwave, Soxhlet extraction, hydrodistillation, and cold maceration. Integrative Medicine Research, 4, 171-177.

Yang, C. S., Landau, J. M., Huang, M. T., \& Newmark, H. L. (2001). Inhibition of carcinogenesis by dietary polyphenolic compounds. Annual Review of Nutrition $21,381-406$. 